ARTICLE

https://doi.org/10.1038/s41467-019-11349-9

\title{
Atomic-scale engineering of indium oxide promotion by palladium for methanol production via $\mathrm{CO}_{2}$ hydrogenation
}

\author{
Matthias S. Frei ${ }^{1}$, Cecilia Mondelli id ${ }^{1}$, Rodrigo García-Muelas (iD ${ }^{2}$, Klara S. Kley', Begoña Puértolas ${ }^{1}$, \\ Núria López (1) ${ }^{2}$, Olga V. Safonova (10 ${ }^{3}$, Joseph A. Stewart [1] ${ }^{4}$, Daniel Curulla Ferré ${ }^{4}$ \& Javier Pérez-Ramírez (i] ${ }^{1}$
}

Metal promotion is broadly applied to enhance the performance of heterogeneous catalysts to fulfill industrial requirements. Still, generating and quantifying the effect of the promoter speciation that exclusively introduces desired properties and ensures proximity to or accommodation within the active site and durability upon reaction is very challenging. Recently, $\ln _{2} \mathrm{O}_{3}$ was discovered as a highly selective and stable catalyst for green methanol production from $\mathrm{CO}_{2}$. Activity boosting by promotion with palladium, an efficient $\mathrm{H}_{2}$-splitter, was partially successful since palladium nanoparticles mediate the parasitic reverse water-gas shift reaction, reducing selectivity, and sinter or alloy with indium, limiting metal utilization and robustness. Here, we show that the precise palladium atoms architecture reached by controlled co-precipitation eliminates these limitations. Palladium atoms replacing indium atoms in the active $\ln _{3} \mathrm{O}_{5}$ ensemble attract additional palladium atoms deposited onto the surface forming low-nuclearity clusters, which foster $\mathrm{H}_{2}$ activation and remain unaltered, enabling record productivities for $500 \mathrm{~h}$.

\footnotetext{
${ }^{1}$ Institute for Chemical and Bioengineering, Department of Chemistry and Applied Biosciences, ETH Zurich, Vladimir-Prelog-Weg 1, 8093 Zurich, Switzerland. ${ }^{2}$ Institute of Chemical Research of Catalonia (ICIQ), The Barcelona Institute of Science and Technology, Av. Països Catalans 16,43007 Tarragona, Spain. ${ }^{3}$ Paul Scherrer Institute, Forschungsstrasse 111, 5232 Villigen, Switzerland. ${ }^{4}$ Total Research \& Technology Feluy, Zone Industrielle Feluy C, 7181 Seneffe, Belgium. Correspondence and requests for materials should be addressed to J.P.-R. (email: jpr@chem.ethz.ch)
} 
M etal promotion is a key strategy in heterogeneous catalysis to enhance activity, selectivity, and stability of catalytic centers by tuning of their electronic and geometric properties. Numerous industrial catalysts rely on promoters to comply with requirements related to reactor scale, operating conditions, and atom economy, in order to minimize costs, waste production, and energy input, ensuring higher profits and environmental friendliness ${ }^{1}$. To maximize benefits, the added element should carry the required functionality without introducing detrimental properties, be located in high vicinity to or within the active sites, and remain unperturbed upon use in the targeted reaction. Fulfilling all these goals is a demanding task that necessitates precision synthesis methods defined based on information provided by in-depth characterization, mechanistic elucidation, and testing about the most suitable promoter speciation $^{2-4}$. The latter is a broad-term embracing identity, oxidation state, and molecular structure of the chemical species.

In the frame of research efforts devoted to mitigating global warming and overcoming our reliance on fossil feedstocks ${ }^{5-16}$, promotion by palladium has been attempted on a breakthrough catalyst, $\mathrm{In}_{2} \mathrm{O}_{3}$, recently discovered for $\mathrm{CO}_{2}$ hydrogenation to methanol ${ }^{17,18}$. Indeed, although this reducible oxide is very selective and durable, especially when supported on $\mathrm{ZrO}_{2}$, owing to the presence of frustrated Lewis pairs ${ }^{19,20}$ and singleensembles $^{21,22}$, its $\mathrm{H}_{2}$-splitting ability is limited ${ }^{23}$. Palladium was shown to generate bulk intermetallic compounds with indium ${ }^{24,25}$, which were superior to $\mathrm{In}_{2} \mathrm{O}_{3}$ in liquid-phase $\mathrm{CO}_{2}$ hydrogenation ${ }^{26}$, but were exclusively active for the competitive reverse water-gas shift (RWGS) reaction when applied in the gas phase as nanoparticles supported on silica ${ }^{27}$. A synthetic method devised to deposit palladium nanoparticles on $\operatorname{In}_{2} \mathrm{O}_{3}$ minimizing alloy formation ${ }^{28}$ led to a system displaying enhanced methanol formation, which was ascribed to the higher availability of activated hydrogen, fostering the desired hydrogenation reaction and vacancy formation on the oxide surface. These contrasting findings highlight that the true relevant speciation and action mechanism of palladium are poorly understood. More importantly, to maximize the promoting effect and thus process-level advantages, the $\mathrm{H}_{2}$-splitting ability of palladium should be exploited while minimizing its high efficacy for the RWGS reaction as a stand-alone metallic phase ${ }^{29-31}$. As single palladium atoms supported on carbon nitride are active in alkyne semihydrogenation and photocatalytic $\mathrm{CO}_{2}$ reduction ${ }^{32-34}$ and possess distinct electronic properties compared to agglomerated palladium, calculations indicate that the (R)WGS reaction on $\operatorname{Pd}(111)$ requires at least three palladium atoms ${ }^{35}$, and the selectivity of platinum on $\mathrm{MoS}_{2}$ in $\mathrm{CO}_{2}$ hydrogenation was dictated by the cluster mono-/binuclearity ${ }^{36}$, we conceived atomic dispersion as a strategy to curtail detrimental effects while preserving beneficial attributes. This approach would simultaneously grant improved metal utilization and robustness, if palladium atoms are well anchored to the $\operatorname{In}_{2} \mathrm{O}_{3}$ structure. Aiming at deriving synthesis-structure-performance relations, we emphasized experimental methods as well as theoretical means, which comprise a prominent tool to uncover the impact of structure on activity and selectivity ${ }^{37-39}$ but have rarely been applied to link preparation to structure.

Here, we introduce a co-precipitation method effective in incorporating isolated palladium atoms in the $\mathrm{In}_{2} \mathrm{O}_{3}$ lattice forming low-nuclearity palladium clusters anchored to the active site, as elucidated by state-of-the-art characterization and density functional theory (DFT) investigations. Kinetic and long-term tests show how this speciation overcomes selectivity and stability limitations associated with palladium nanoparticles, rationalizing the unparalleled performance of this catalyst for $\mathrm{CO}_{2}$-based methanol synthesis.

\section{Results}

Impact of promoter nature and loading, and synthesis method. We prepared palladium-promoted $\mathrm{In}_{2} \mathrm{O}_{3}$ by co-precipitation and a sol-gel method targeting an atomic palladium distribution in the oxide, and applied spray deposition and dry and wet impregnation as well as simultaneous chemical reduction of palladium and indium salts to attain benchmark materials comprising palladium nanoparticles and a PdIn intermetallic compound. All catalysts possessed sufficiently high surface area and pore volume $\left(S_{\mathrm{BET}}>100 \mathrm{~m}^{2} \mathrm{~g}^{-1}, V_{\text {pore }}>0.3 \mathrm{~cm}^{3} \mathrm{~g}^{-1}\right)$ and the nominal palladium loading of 0.75 wt.\% was closely matched (Supplementary Table 1). Their catalytic performance was assessed in $\mathrm{CO}_{2}$ hydrogenation to methanol at $553 \mathrm{~K}$ and $5 \mathrm{MPa}$ and compared with that of pure $\operatorname{In}_{2} \mathrm{O}_{3}$. The presence of palladium increased the methanol space-time yield (STY) in all cases, except for the intermetallic solid. The co-precipitated catalyst (CP) was the best material $\left(S T Y=0.61 \mathrm{~g}_{\mathrm{MeOH}} \mathrm{h}^{-1} \mathrm{~g}_{\text {cat }}{ }^{-1}\right)$, closely followed by that produced by dry impregnation (DI). Reference solids comprising palladium introduced into the inert $\mathrm{TiO}_{2}$ support by $\mathrm{CP}$ and DI mainly produced $\mathrm{CO}$, as expected from the reported RWGS activity of palladium nanoparticles ${ }^{31}$. After confirming the superiority of palladium with respect to other typical hydrogenation metals (Supplementary Fig. 1), we unraveled the impact of its loading by testing CP and DI materials containing $0.25-10$ wt.\% Pd (Fig. 1a). The initial loading of 0.75 wt.\% turned out to be optimal, as the STY was inferior at lower contents and remained equal or dropped for higher amounts. Interestingly, the CP catalyst with this palladium content retained a STY of $0.60 \mathrm{~g}_{\mathrm{MeOH}} \mathrm{h}^{-1} \mathrm{~g}_{\mathrm{cat}}{ }^{-1}$ for $93 \mathrm{~h}$ on stream after a minimal initial deactivation, whereas the DI counterpart lost half as of its productivity after $74 \mathrm{~h}$ (Fig. 1b). Comparing the methanol selectivity $\left(S_{\mathrm{MeOH}}\right)$ over CP and DI catalysts and $\mathrm{In}_{2} \mathrm{O}_{3}$ at a $\mathrm{CO}_{2}$ conversion of $3 \%(97,78$, and $89 \%$, respectively, Fig. 1c) revealed that palladium has a beneficial effect on the product distribution when added through CP but not via DI.

Experimental description of palladium sites. CP and DI samples were studied through a battery of characterization techniques to elucidate the palladium speciation. X-ray diffraction (XRD) confirmed the bixbyite (i.e., a defective fluorite-type) structure of $\mathrm{In}_{2} \mathrm{O}_{3}$ in both systems (Supplementary Fig. 2), the lowest-energy surface of which presents a protruding $\operatorname{In}_{3} \mathrm{O}_{5}(\mathrm{O})$ substructure, which generates the active site in acetylene and $\mathrm{CO}_{2}$ hydrogenation after removal of the $(\mathrm{O})$ atom ${ }^{21}$, and an adjacent sunken region. The average particle size of $\mathrm{In}_{2} \mathrm{O}_{3}$ was calculated at $9 \mathrm{~nm}$ for the fresh materials and increased to 15 and $25 \mathrm{~nm}$ for used CP and DI catalysts, respectively. Moderate sintering was also observed earlier for unpromoted $\operatorname{In}_{2} \mathrm{O}_{3}{ }^{17,22}$. A weak reflection at $39.5^{\circ} 2 \theta$ specific to $\mathrm{Pd}^{0}$ was detected only for the used DI material. High angle annular dark-field scanning transmission electron microscopy (HAADF-STEM) images and indium and palladium maps acquired by energy-dispersive X-ray spectroscopy (EDX) indicate that palladium is extremely well dispersed in the fresh samples (Fig. 2). The CP material used in the reaction for $93 \mathrm{~h}$ appeared virtually unaltered. In contrast, $\operatorname{In}_{2} \mathrm{O}_{3}$ particles increased their size to ca. $30 \mathrm{~nm}$ and palladium nanoparticles formed using the DI catalyst for $74 \mathrm{~h}$ (Supplementary Fig. 2), the latter having an average size of $2.8 \mathrm{~nm}$ based on high resolution transmission electron microscopy (HRTEM, Supplementary Figs. 3 and 4). A determination of the palladium dispersion in $\mathrm{CP}$ and DI catalysts was attempted by $\mathrm{H}_{2}$ and $\mathrm{CO}$ chemisorption. The reduction behavior of the fresh catalysts was studied (Supplementary Fig. 5) through temperature-programmed reduction with $\mathrm{H}_{2}$ and $\mathrm{CO}\left(\mathrm{H}_{2}\right.$-TPR and $\mathrm{CO}$-TPR $)$ and temperatureprogrammed desorption of $\mathrm{CO}$ (CO-TPD) to identify suitable 

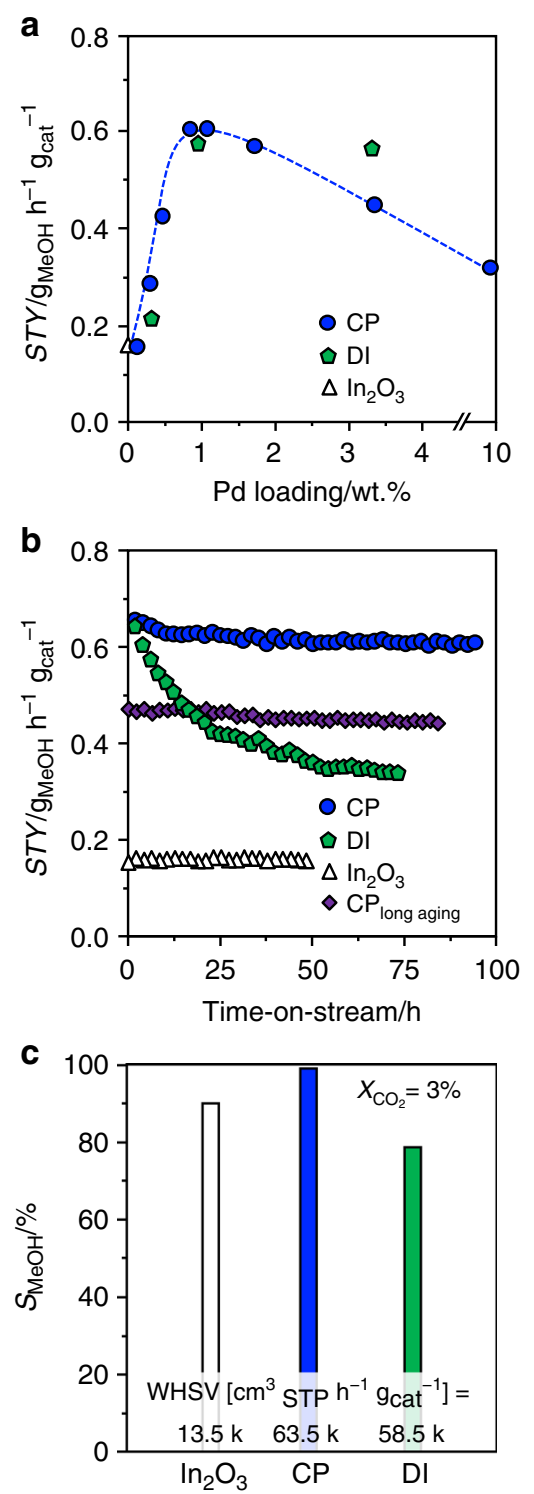

Fig. 1 Catalytic performance of palladium-promoted $\ln _{2} \mathrm{O}_{3}$ catalysts. a Impact of Pd loading on methanol space-time yield (STY) after $1 \mathrm{~h}$ on stream for palladium-promoted $\ln _{2} \mathrm{O}_{3}$ catalysts obtained by co-precipitation (CP) and dry impregnation (DI), b temporal evolution of the methanol STY for $C P$ and DI catalysts, with pure $\ln _{2} \mathrm{O}_{3}$ as a reference, and c methanol selectivity over the same materials after $48 \mathrm{~h}$ on stream, when a $\mathrm{CO}_{2}$ conversion of $3 \%$ is attained by operation at the indicated WHSV. $\ln \mathbf{b}$, data of an additional CP catalyst is presented that was aged for 200 instead of 1 h. Reaction conditions: $T=553 \mathrm{~K}, P=5 \mathrm{MPa}, \mathrm{H}_{2}: \mathrm{CO}_{2}=4$, and $W H S V=$ $24,000 \mathrm{~cm}^{3}$ STP $^{-1} \mathrm{gcat}^{-1}$ unless otherwise stated

conditions for the reductive pre-treatment and the volumetric analysis. Barely measurable $\mathrm{H}_{2}$ and $\mathrm{CO}$ uptakes were registered for used DI samples (Supplementary Fig. 5). We put forward strong metal support interactions (SMSI) and/or Pd-In alloying as plausible reasons for the dramatic change in electronic properties of palladium particles in promoted $\operatorname{In}_{2} \mathrm{O}_{3}$ samples. The similar palladium dispersion determined for a $\mathrm{Pd} / \mathrm{TiO}_{2}$ material with the same promoter loading and average particle size as DI $74 \mathrm{~h}$ (Supplementary Fig. 4), a catalyst for which the SMSI phenomenon has been widely documented ${ }^{40}$, supports our hypothesis. No and a very weak CO chemisorption was detected by diffuse-reflectance infrared Fourier transform spectroscopy (CO-DRIFTS, Supplementary Fig. 6) for fresh and used CP samples and DI $74 \mathrm{~h}$, respectively. The first evidence agrees with studies reporting that isolated charged palladium species do not adsorb $\mathrm{CO}^{32}$ and isolated metallic Pd atoms weakly interact with $\mathrm{CO}$ at close-to-liquid-nitrogen temperatures ${ }^{41}$, and the second with the volumetric analysis. Based on electron microscopy, atomic dispersion of surface palladium species is plausible for fresh CP and DI catalysts and CP $1 \mathrm{~h}$, while a value of $42 \%$ was estimated for DI $74 \mathrm{~h}$ considering the TEM-determined average particle size and a spherical geometry ${ }^{42}$.

According to X-ray photoelectron spectroscopy (XPS), the fresh $\mathrm{CP}$ and DI catalysts exclusively contained $\mathrm{Pd}^{2+}$ species (Fig. 3a), which chiefly reduced to $\mathrm{Pd}^{0}$ upon use in the reaction for $1 \mathrm{~h}$. Residual $\mathrm{Pd}^{2+}$ species are likely owing to the short exposure of the samples to air for the ex situ analysis, as no uptake possibly related to the reduction of oxidized palladium was evidenced by $\mathrm{H}_{2}$-TPR for $\mathrm{CP}$ used for $1 \mathrm{~h}$ at $\mathrm{H}_{2}: \mathrm{CO}_{2}$ ratios of 4 and 2 (Supplementary Fig. 7). Despite the same bulk metal loading, palladium is almost 3-times more abundant on the surface of the DI catalyst (1.1 at.\%, Supplementary Table 2) than on the CP sample (0.4 at.\%), which supports Pd incorporation throughout the oxide crystals in the latter. After removing ca. $4 \mathrm{~nm}$ of the surface by sputtering with $\mathrm{Ar}^{+}$ions, metallic palladium was still detected for DI $1 \mathrm{~h}$. As this material only contains palladium deposited onto the $\operatorname{In}_{2} \mathrm{O}_{3}$ surface, the signal of the promoter should vanish. Still, information on the bulk is obviously mixed with that of the surface, as we are dealing with a polycrystalline material with an average particle size of ca. $8 \mathrm{~nm}$, and XPS has a penetration depth of ca. $6 \mathrm{~nm}$. For CP $1 \mathrm{~h}$, palladium in oxidized form was evidenced for the sputtered sample, suggesting that the promoter in the interior of the oxide is not reduced upon reaction. The Pd3d signal of CP $16 \mathrm{~h}$ exhibited unaltered shape and intensity, as expected based on the stability of this material. In contrast, the surface Pd content for the DI material almost halved after $16 \mathrm{~h}$ on stream, in agreement with its sintering.

To further elucidate the palladium speciation in the two systems, X-ray absorption near edge structure (XANES) and extended X-ray absorption fine structure (EXAFS, Fig. 3b) spectroscopy were measured at the Pd K-edge. The fresh CP material contains isolated $\mathrm{Pd}^{2+}$ species, which possess four $\mathrm{O}$ neighbors (Pd-O scattering path, Supplementary Fig. 8 and Supplementary Table 3) in square geometry at a distance of ca. $2.01 \AA$ in the first coordination shell and are embedded in $\operatorname{In}_{2} \mathrm{O}_{3}$, as evidenced by the second coordination shell of Pd following the Pd-O-In scattering path. Accordingly, they are strongly bound to the oxide surface or can be in bulk lattice positions if oxygen vacancies are present in their first coordination shell. For the fresh DI catalyst, the O shell around Pd is similar to that in the $\mathrm{CP}$ material and in $\mathrm{PdO}$, but the interaction with the $\mathrm{In}_{2} \mathrm{O}_{3}$ lattice is much weaker, as hinted by the low coordination number of the $\mathrm{Pd}-\mathrm{O}-\mathrm{In}$ scattering path. Consequently, palladium is likely present as an oxide highly dispersed on $\operatorname{In}_{2} \mathrm{O}_{3}$. After $1 \mathrm{~h}$ on stream, palladium becomes metallic in both catalysts forming nanostructures smaller than in the intermetallic reference, which contains nanoparticles of ca. $2 \mathrm{~nm}$. In the CP material, these actually comprise clusters of $4-5$ atoms, which do not grow significantly upon longer use in the reaction. Due to the similar scattering factors of palladium and indium, their composition can be described as $\mathrm{Pd}_{x} \mathrm{In}_{4-x}$ tetramers or $\mathrm{Pd}_{x+1} \mathrm{In}_{4-x}$ pentamers. The resemblance of the XANES spectrum of the used CP sample to that of the intermetallic reference suggests that these clusters include both elements. As the Pd K-edge was probed, one atom must be Pd. As Pd-O-In scattering is detected and the palladium amount is low, it is unlikely that the remaining 3-4 atoms are all $\mathrm{Pd}$ atoms. Considering that palladium modifies the intrinsic activity of the catalytic site in indium oxide, it is reasonable that 
a
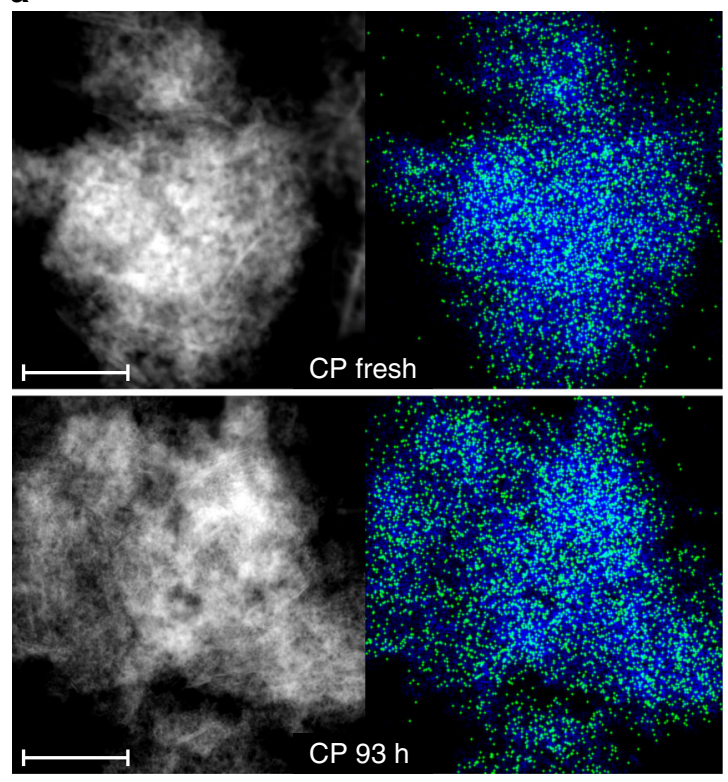

b
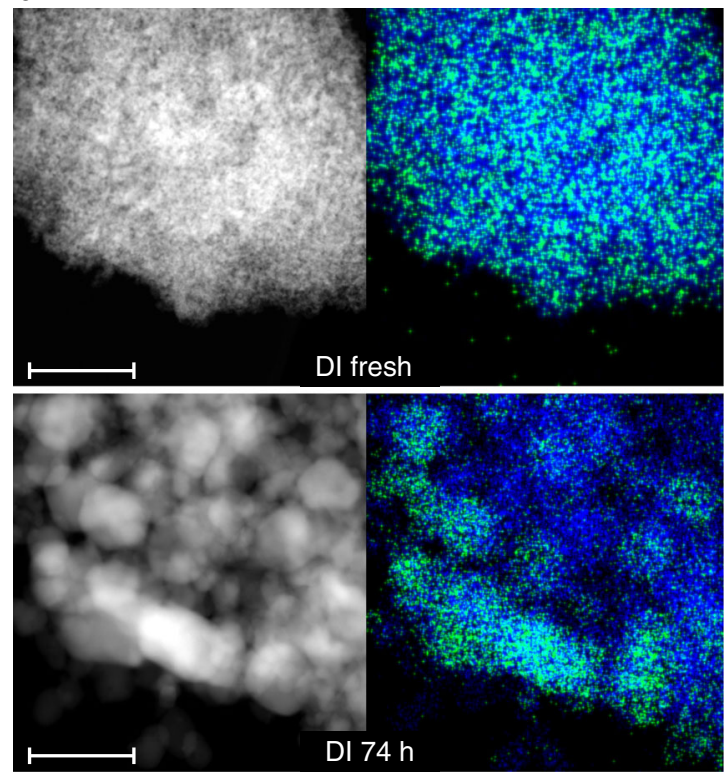

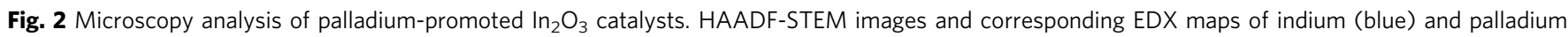
(green) for the catalysts produced by $\mathbf{a}$ CP and $\mathbf{b}$ DI with 0.75 wt.\% Pd in fresh form and after the tests depicted in Fig. 1 b. The scale bar in all panels is $50 \mathrm{~nm}$

palladium replaces one of the In atoms in the $\mathrm{In}_{3} \mathrm{O}_{5}$ ensemble. Hence, most likely configurations are $\mathrm{Pd}_{2} \mathrm{In}_{2}$ and $\mathrm{Pd}_{3} \mathrm{In}_{2}$. These species can only be generated by $\mathrm{CP}$ and with low palladium loading, as the Pd-O-In scattering is absent in the EXAFS spectra of the CP catalyst with 3.5 wt.\% $\mathrm{Pd}$ and the DI solid. Confirmation of the low clustering degree of palladium was attained by time of flight-secondary ions mass spectrometry (TOF-SIMS). Ionic species emitted from the surface of CP $1 \mathrm{~h}$ predominantly contained a single $\mathrm{Pd}$ atom, and no ions containing $>2 \mathrm{Pd}$ atoms. Relevantly, an equivalent result was attained for $\mathrm{CP} 16 \mathrm{~h}$, in line with the high resilience of palladium to aggregate in the $\mathrm{CP}$ catalyst (Fig. 3c).

To investigate the promoter impact on vacancy formation, $\mathrm{H}_{2}$ TPR at the process pressure (5 MPa, Fig. $3 \mathrm{~d}$ and Supplementary Fig. 9) was conducted. Surface reduction of $\mathrm{In}_{2} \mathrm{O}_{3}$ occurred at much lower temperatures for all promoted catalysts than for the unpromoted oxide (292-313 versus $495 \mathrm{~K}$ ), highlighting the assistance of palladium in $\mathrm{H}_{2}$ splitting. The signal of the DI sample is more intense, hinting at a higher number of vacancies. For the same solid, an additional signal at $249 \mathrm{~K}$ related to palladium reduction was detected, which supports the segregation of the promoter from $\operatorname{In}_{2} \mathrm{O}_{3}$. The findings are further corroborated by deconvolution of the XPS O1s signal (Fig. 3e): CP and DI used for $1 \mathrm{~h}$ contain a comparable amount of vacancies and after $16 \mathrm{~h}$ on stream their concentration remains practically unaltered for the CP catalyst, whereas it increases by $29 \%$ for the DI system. The latter sample also features a greater amount of surface hydroxides $(25 \%$ more than CP), likely caused by dissociated hydrogen spilled from palladium particles to $\mathrm{In}_{2} \mathrm{O}_{3}$. A greater abundance of vacancies is also supported by the higher quantity of $\mathrm{CO}_{2}$ desorbed from this catalyst than from CP $1 \mathrm{~h}$ (Supplementary Fig. 10). To further unravel changes of the oxide by palladium addition, ${ }^{115} \mathrm{In}$ solid-state nuclear magnetic resonance (NMR) spectra were acquired to selectively probe indium. Notably, the large quadrupolar interaction of the NMR active spin 9/2 In nucleus makes this a challenging analysis, which has never been reported for a bulk indium-based material. Two magnetically inequivalent types of In atoms were detected in the spectrum of cubic $\operatorname{In}_{2} \mathrm{O}_{3}$, one causing the central transition with maximum at $280 \mathrm{ppm}$ and the other originating two peaks at 3750 and $-6250 \mathrm{ppm}$ (Fig. 3f). The asymmetry of these functions is owing to quadrupolar coupling and some disorder, owing to the small size of the oxide particles. The spectra of fresh $\mathrm{CP}$ and DI catalysts resemble that of $\operatorname{In}_{2} \mathrm{O}_{3}$, but are noisier, mostly because of the diamagnetic character of the $\mathrm{PdO}$ present. Additional signals between 5000 and 8000 and -7000 and $11,000 \mathrm{ppm}$ were observed for CP $1 \mathrm{~h}$ and DI $1 \mathrm{~h}$ owing to the formation of oxygen vacancies, which modify the electronic environment of adjacent In nuclei. Although these are equivalent in all used samples, the particles size of $\operatorname{In}_{2} \mathrm{O}_{3}$ in DI $16 \mathrm{~h}$ is larger, implying a higher density of vacancies per surface area in this material. The analysis further indicates that the $\operatorname{In}_{2} \mathrm{O}_{3}$ structure must be preserved in models of promoted catalysts selected for theoretical modeling.

Theoretical description of palladium sites and mechanism. Different palladium-promoted $\operatorname{In}_{2} \mathrm{O}_{3}(111)$ surfaces were analyzed to unravel the most likely environment of the noble metal in $\mathrm{CP}$ and DI catalysts (Fig. 3g). As palladium and indium cations are atomically mixed upon $\mathrm{CP}$, palladium can replace indium in the $\mathrm{In}_{2} \mathrm{O}_{3}$ lattice. However, DFT simulations indicate that palladium is substantially more stable at a surface rather than a bulk position, i.e., segregation is favored towards position $\mathbf{1}$ in the $\mathrm{In}_{3} \mathrm{O}_{5}(\mathrm{O})$ ensemble $(-0.87 \mathrm{eV})$. The replacement of a second or third In atom in the ensemble is unfavored, with islanding energies taking positive values (up to $0.75 \mathrm{eV}$, Supplementary Table 4). The Pd coordination is square planar, with a $\mathrm{Pd}-\mathrm{O}$ distance of $2.05 \AA$, in good agreement with the experimental EXAFS data for the fresh sample. The substitution of Pd atoms in the $\mathrm{In}_{3} \mathrm{O}_{5}(\mathrm{O})$ protrusion promotes the formation of two oxygen vacancies upon reaction (Supplementary Fig. 11), creating a $\mathrm{PdIn}_{2} \mathrm{O}_{4}$ site. Hence, $\mathrm{Pd}$ species become more reduced, as evident from the core-level Pd3d spectra and the Bader charges (Fig. 3g). The $P d_{x} \operatorname{In}_{4-x}$ and $P d_{x+1} \operatorname{In}_{4-x}$ clusters identified by EXAFS in the used CP sample can be rationalized by the spontaneous migration of $\mathrm{Pd}$ atoms from the small depression (pocket) to the adjacent $\mathrm{PdIn}_{2} \mathrm{O}_{4}$ sites. Still, an ensemble with $2 \mathrm{Pd}$ atoms likely is more representative of the actual catalyst than one with $3 \mathrm{Pd}$ atoms, as 


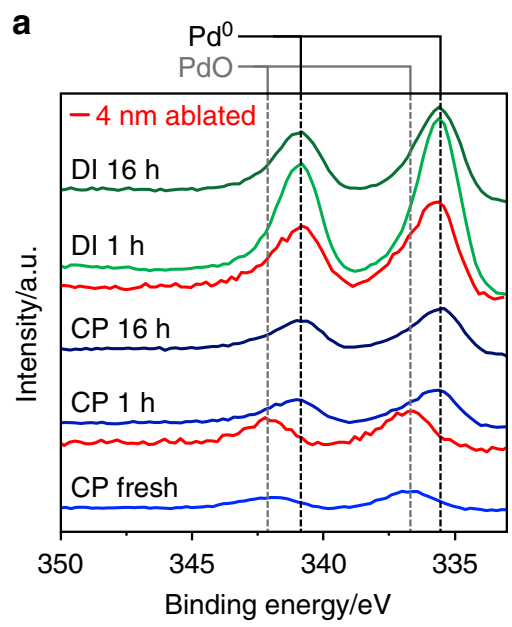

d

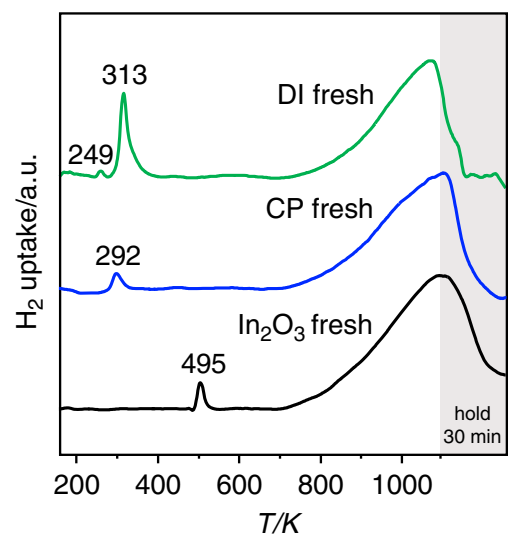

b

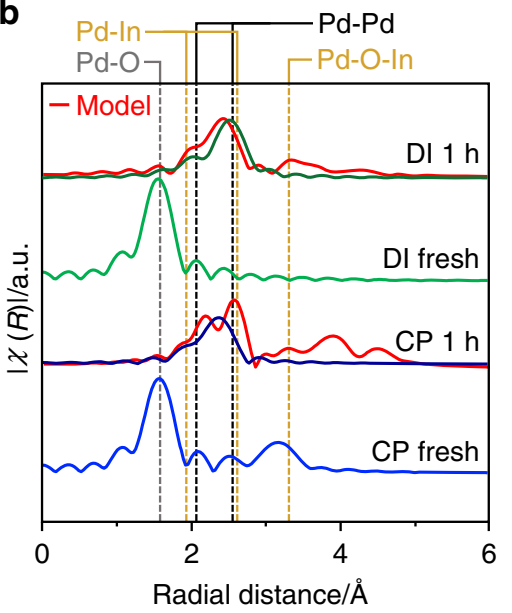

e

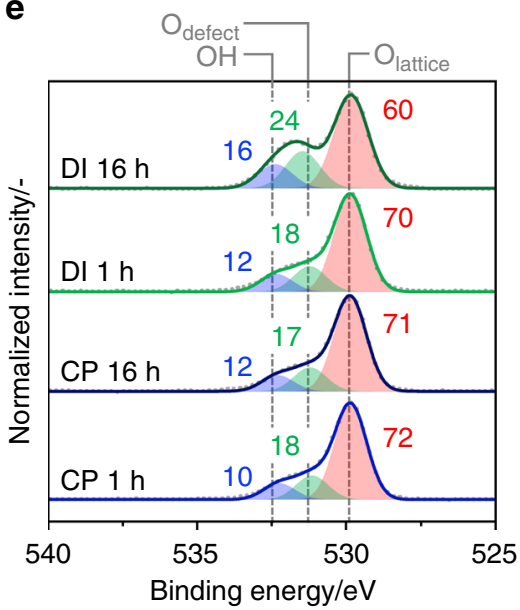

c

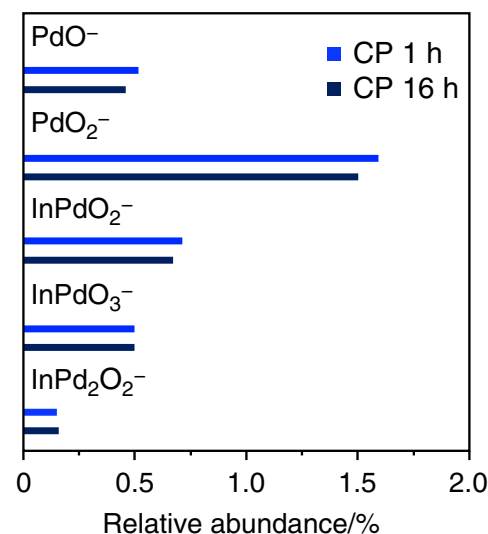

f

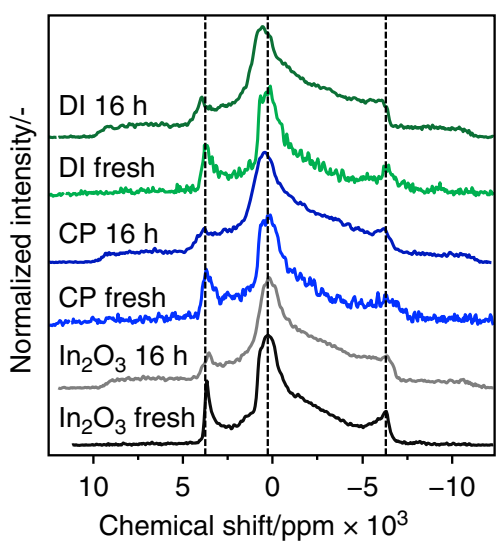

g

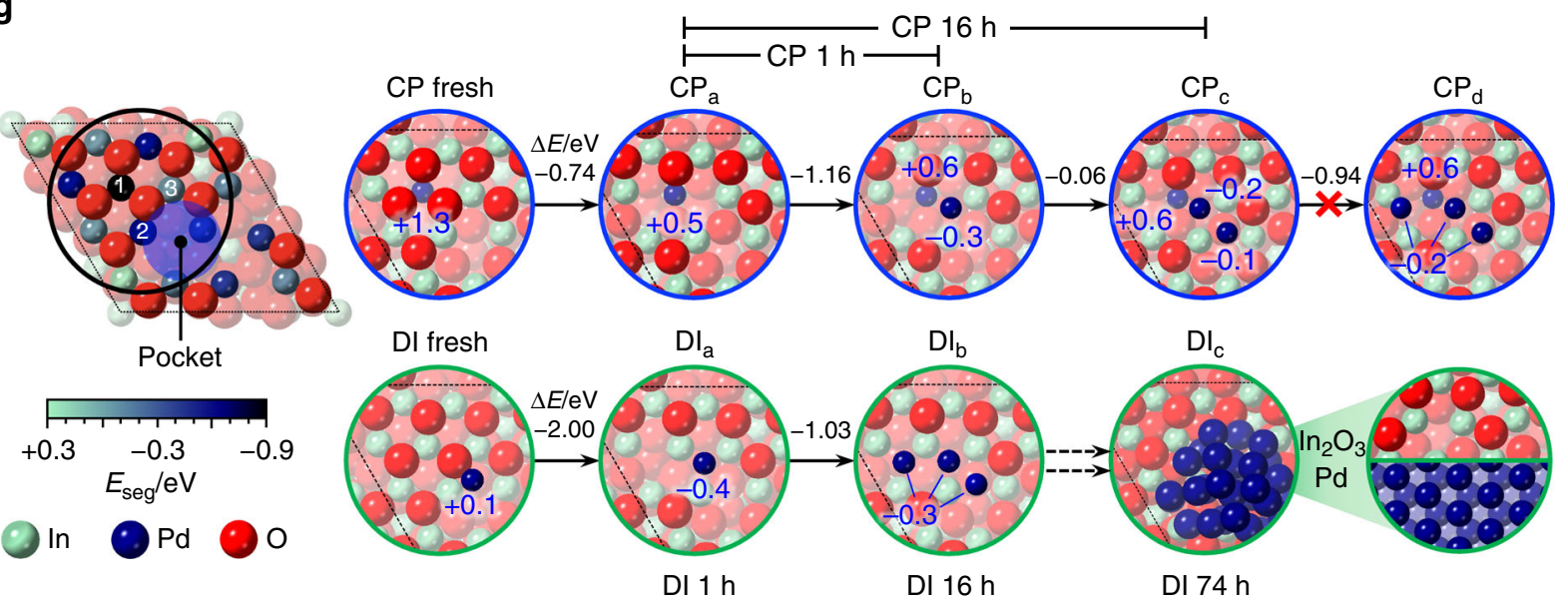

Fig. 3 Experimental and theoretical elucidation of palladium-promoted $\ln _{2} \mathrm{O}_{3}$ catalysts. a XPS Pd3d core-level spectra, and $\mathbf{b}$ Pd-K-edge EXAFS spectra of the $\mathrm{CP}$ and $\mathrm{DI}$ catalysts in fresh form and after use in $\mathrm{CO}_{2}$ hydrogenation for $1 \mathrm{~h}$. EXAFS spectra simulated for the latter are added in red. The dashed lines mark expected positions of signals of the species indicated ${ }^{52-54}$. c Abundance of Pd-containing fragments emitted from the surface of used $\mathrm{CP}$ and $\mathrm{DI}$ materials in TOF-SIMS analysis. $\mathbf{d ~} \mathrm{H}_{2}$-TPR profiles at $5 \mathrm{MPa}$ of the fresh CP and DI catalysts with $\mathrm{In}_{2} \mathrm{O}_{3}$ as a reference. e XPS O1s core-level spectra of CP and DI catalysts after use for 1 and $16 \mathrm{~h}$. The contribution of lattice oxygen, oxygen close to a defect, and oxygen in a hydroxyl group retrieved from deconvolution are marked in red, green, and blue, respectively, and labeled with their relative abundance in \%. $\mathbf{I} \ln ^{115} \mathrm{NMR}$ spectra collected for pure $\ln { }_{2} \mathrm{O}_{3}$ and the $\mathrm{CP}$ and $\mathrm{DI}$ catalysts in fresh form and after use for $16 \mathrm{~h} . \mathbf{g}$ (left) Structure of a regularly terminated $\ln _{2} \mathrm{O}_{3}(111)$ surface featuring, owing to the strong anisotropy, a depression (pocket) where Pd atoms preferentially accommodate in the fresh DI catalyst. The coloring of In atoms at the surface represents the energy associated with their replacement by palladium $\left(E_{\mathrm{seg}}\right.$, in eV), which takes place upon CP. 1-3 mark the lattice positions most preferred by the promoter. (right) Initial palladium-promoted $\operatorname{In}_{2} \mathrm{O}_{3}(111)$ surface models for the CP and DI catalysts and their evolution to account for structural modifications occurring upon their use for in the reaction. The energy difference between states for each transition $(\Delta E$, in $\mathrm{eV})$ and the Bader charges of the $\mathrm{Pd}$ atoms $\left(q_{\mathrm{B}}\right.$ in $\left.\left|\mathrm{e}^{-}\right|\right)$are indicated in blue. Atoms are shaded with a progressively lighter color upon increasing distance from the surface towards the bulk 
the fresh catalyst contains only few extra-lattice Pd atoms (Supplementary Table 2), the addition of a $\mathrm{Pd}$ atom to a palladium dimer is thermoneutral, and configurational entropy favors dispersion ${ }^{43}$. Notably, the electronic structure of $\mathrm{Pd}_{2} \mathrm{In}_{4} \mathrm{O}_{4}$ ensembles strongly differs from that of $\mathrm{In}_{2} \mathrm{O}_{3}$-supported $\mathrm{Pd}$ nanoparticles ${ }^{28}$ and PdIn intermetallics ${ }^{27,44}$ based on local densities of states calculations (Supplementary Fig. 12). However, CP models with $0-4 \mathrm{Pd}$ atoms were considered for the reaction mechanism study detailed below.

In the case of DI, Pd atoms are deposited onto an already formed oxide surface preferentially allocating in its depressions. Upon exposure to the reaction mixture, the oxidic palladium species lose the ligands becoming metallic and tend to generate nanoparticles since (i) clustering energies are favorable $(-0.4$ to $-1.0 \mathrm{eV}$ ), (ii) $\mathrm{Pd}$ atoms on the surface are more abundant than in the CP material (Supplementary Table 2), and (iii) the barriers for the diffusion of Pd atoms between pockets are mild (Supplementary Fig. 13). This phase separation leads to a DI catalyst exhibiting $\operatorname{In}_{3} \mathrm{O}_{5}(\mathrm{O})$ ensembles and $\mathrm{Pd}$ nanoparticles as active sites. The latter easily activate $\mathrm{H}_{2}$ and, by spillover, promote the formation of additional vacancies on the oxide surface (Fig. $3 \mathrm{~g}$ ). Simulated EXAFS spectra of the active structures in CP and DI solids are in reasonable agreement with experimental findings (Fig. 3b). Figure 4 presents the most significant CP and DI catalysts' models and their features, highlighting the remarkable matching of information derived from experiments and from theory.

Gibbs energy profiles for methanol and CO formation from $\mathrm{CO}_{2}$ were calculated based on the elementary steps found optimal for $\mathrm{In}_{2} \mathrm{O}_{3}$. The activation of the $\mathrm{CP}$ catalyst starts with $\mathrm{H}_{2}$ dissociation onto two $\mathrm{O}$ atoms located nearby the lattice palladium species, followed by transfer of one $\mathrm{H}$ atom to form water, which desorbs creating a vacancy. A second vacancy is generated similarly (Supplementary Fig. 11). This can be followed by the creation of active sites with higher palladium nuclearities, i.e., $\mathrm{Pd}_{x} \operatorname{In}_{2} \mathrm{O}_{4}(x>1)$, through palladium migration from pockets to $\mathrm{PdIn}_{2} \mathrm{O}_{4}$ ensembles. For the DI catalyst, vacancy formation is equivalent, but $\mathrm{H}_{2}$ is split on Pd atoms in the pockets. Notably, $\mathrm{H}_{2}$ dissociation on $\mathrm{In}_{2} \mathrm{O}_{3}$ is heterolytic, whereas it is homolytic in the presence of intra- or extra-lattice $\mathrm{Pd}$ atoms, which reduce the $\mathrm{H}_{2}$ splitting barrier. $\mathrm{CO}_{2}$ hydrogenation to methanol on $\mathrm{CP}$ and DI surface models with 1-4 Pd atoms comprises $\mathrm{CO}_{2}$ adsorption (Supplementary Figs. 14-17), followed by $\mathrm{H}_{2}$ activation and sequential transfer of the two adsorbed $\mathrm{H}$ atoms to the $\mathrm{C}$ atom. Further $\mathrm{H}_{2}$ activation enables the hydrogenation of one $\mathrm{O}$ atom leading to $\mathrm{H}_{2} \mathrm{COOH}$. Cleavage of the $\mathrm{OH}$ group generates a $\mathrm{CH}_{2} \mathrm{O}$ species, which is hydrogenated at the $\mathrm{C}$ and the $\mathrm{O}$ centers, in this order, producing methanol. The latter then desorbs. In the RWGS reaction, $\mathrm{CO}_{2}$ adsorbs on the surface once a third vacancy is created, and is hydrogenated at one $\mathrm{O}$ atom. The formed $\mathrm{OH}$ group is cleaved and moves to a vacancy, whereas CO desorbs. Based on the span model, CP surfaces with 1-3 Pd atoms and the DI surface with $1 \mathrm{Pd}$ atom are selective towards methanol and to a greater extent than bulk $\operatorname{In}_{2} \mathrm{O}_{3}$, whereas, for the CP surface with $4 \mathrm{Pd}$ atoms and the DI surface with $3 \mathrm{Pd}$ atoms, the intrinsic activity of palladium for the RWGS reaction dominates and $\mathrm{CO}$ is the favored product. This agrees with the prerequisite of 3 extralattice $\mathrm{Pd}$ atoms to mediate the water-gas shift reaction on $\mathrm{TiO}_{2^{-}}$ supported palladium ${ }^{35}$. The fact that the boost in methanol selectivity is limited for the CP model with a sole palladium species and remarkable for those with 2-3 $\mathrm{Pd}$ atoms supports the higher relevance of $\mathrm{Pd}_{2} \mathrm{In}_{2} \mathrm{O}_{4}$ and $\mathrm{Pd}_{3} \mathrm{In}_{2} \mathrm{O}_{4}$ as active sites. Regarding the equilibrated DI catalyst, $\mathrm{CO}_{2}$ hydrogenation can be described as a superposition of RWGS on palladium, i.e., the $\mathrm{Pd}$ (111) surface ${ }^{35,45}$, and methanol and $\mathrm{CO}$ formation on neighboring undoped $\mathrm{In}_{2} \mathrm{O}_{3}{ }^{22}$, the latter being facilitated by hydrogen spillover from adjacent palladium nanoparticles. To account for coverage effects in this complex surface reaction, a microkinetic model was built (vide infra).

Experimental selectivity-promoter nuclearity correlation. Intrigued by the selectivity-nuclearity correlation uncovered by the theoretical studies for CP catalysts, we conducted a complementary experiment to link palladium agglomeration and its impact on methanol selectivity. When the DI catalyst was tested keeping the $\mathrm{CO}_{2}$ conversion at 2-3\% (Supplementary Fig. 18), the methanol selectivity remained at ca. $83 \%$ for $6 \mathrm{~h}$, followed by a linear decline owing to a progressively greater impact of the RWGS reaction till a value of $58 \%$ after $9 \mathrm{~h}$ on stream. Characterization of the specimen retrieved at the end of the test confirmed severe sintering of palladium and $\operatorname{In}_{2} \mathrm{O}_{3}$ (particle sizes of 12 and $28 \mathrm{~nm}$, respectively). A sample generated by a repeated experiment ending before the onset of the selectivity change still showed an extremely high-palladium dispersion based on STEM-EDX, as expected. This supports that agglomerates of only few Pd atoms are required to start favoring the RWGS reaction and highlights the importance of controlling the promoter nanostructure upon synthesis and preserving it upon reaction.

To tackle the former aspect, we explored the impact of the aging time in $\mathrm{CP}$, as continuous dissolution and re-precipitation occur at this stage, which could lead to palladium segregation from $\mathrm{In}_{2} \mathrm{O}_{3}$. For aging times up to $48 \mathrm{~h}$, the methanol selectivity of CP catalysts was unaltered at ca. $80 \%$, hinting that palladium clusters formed still were very small (Supplementary Fig. 19). A sensible difference was observed for the material aged for $200 \mathrm{~h}$ (64\%), which was found to comprise large palladium particles (up to $10 \mathrm{~nm}$ ) as well as finely distributed palladium (Supplementary Fig. 20), with its performance originating from the superposition of these two distinct promoter speciations. The $\operatorname{In}_{2} \mathrm{O}_{3}$ particle size was $12 \mathrm{~nm}$, corroborating dynamic restructuring upon aging. The longer term behavior of this sample evidenced less-pronounced deactivation than for the DI catalyst and a sustained methanol STY intermediate between that of the CP catalyst attained with an aging of $1 \mathrm{~h}$ and the DI solid.

Evaluation of reaction kinetics and catalyst durability. To gain insights into the origin of palladium promotion, the kinetics of $\mathrm{CO}_{2}$ hydrogenation was investigated in detail. An experimental analysis was performed over the $\mathrm{CP}$ catalyst, the DI material used for $48 \mathrm{~h}$, and the $\mathrm{Pd} / \mathrm{TiO}_{2}$ catalyst already serving as a reference for characterization purposes, under the assumption of first order kinetics, as determined for $\operatorname{In}_{2} \mathrm{O}_{3}{ }^{22}$. Moreover, a microkinetic model was developed and applied to all CP and DI models ${ }^{35,45}$. Based on experimental tests at variable temperature (Fig. 5a and Supplementary Fig. 21), the apparent activation energy $\left(E_{\mathrm{a}}\right)$ for $\mathrm{CO}_{2}$ hydrogenation to methanol for the CP catalyst is ca. $20 \%$ lower than that previously estimated for pure $\mathrm{In}_{2} \mathrm{O}_{3}{ }^{22}$, whereas that of the RWGS reaction is equivalent. The microkinetic model (Supplementary Table 6) indicates that the apparent activation energy for methanol production is lowered by 56 or $4 \mathrm{~kJ} \mathrm{~mol}^{-1}$ when 1 or 2 exposed Pd atoms are present, respectively, and the RWGS reaction is hindered by a barrier higher by at least $+80 \mathrm{~kJ} \mathrm{~mol}^{-1}$ compared with $\mathrm{In}_{2} \mathrm{O}_{3}$. This means that competing transformation mainly occurs on unpromoted $\operatorname{In}_{3} \mathrm{O}_{5}{ }^{22}$ and is effectively blocked by the existence of 1 or 2 exposed Pd atoms at promoted sites. When 3 or more exposed Pd atoms are present, the active site starts behaving like metallic palladium, as the barrier of the RWGS reaction is decreased by $-7 \mathrm{~kJ} \mathrm{~mol}^{-1}$ and methanol production is hindered. For the DI sample, methanol synthesis was facilitated to a comparable extent, but the RWGS 
Experiments

Palladium is highly dispersed and mostly embedded in $\ln _{2} \mathrm{O}_{3}$ Contains $\mathrm{Pd}^{2+}$ with square planar coordination Pd-O distance $=2.01 \AA$

Palladium is highly disp
Surface $\mathrm{Pd}^{2+}$ is reduced
$\mathrm{Pd}_{x} \mathrm{In}_{4-x}, \mathrm{Pd}_{x} \mathrm{In}_{5-x}$ clusters
$1-2 \mathrm{Pd}$ atoms
Methanol selectivity super
Palladium is highly disp
Contains Pd ${ }^{2+}$
Palladium starts to cluster
Pd predominates
Methanol selectivity int

Theory

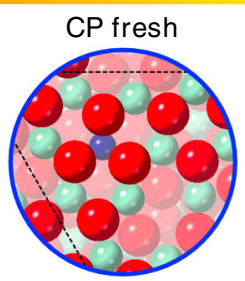

Palladium is highly dispersed and mostly embedded in $\ln _{2} \mathrm{O}_{3}$

Contains $\mathrm{Pd}^{2+}$ with square planar coordination

Pd-O distance: $2.05 \AA$

Palladium is highly dispersed $\mathrm{Pd}$ atoms are reduced $\mathrm{Pd}_{2} \mathrm{In}_{2}$ clusters more likely and efficient

$\mathrm{Pd}_{4} \mathrm{In}_{2}$ not performing

Palladium is highly dispersed Contains $\mathrm{Pd}^{\delta+}$
DI $1 \mathrm{~h}$

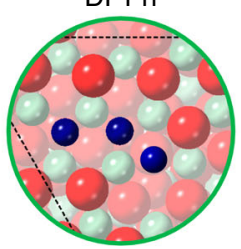

Dl $74 \mathrm{~h}$

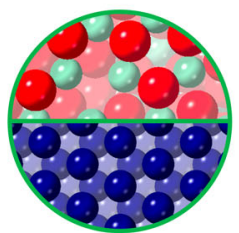

Palladium diffusion barriers are low Palladium starts to cluster $\mathrm{Pd}^{0}$ predominates

$\mathrm{Pd}_{3}$ clusters mainly produce $\mathrm{CO}$

Palladium sinters into nanoparticles Separate sites for RWGS and $\mathrm{CO}_{2}$ hydrogenation to methanol Methanol selectivity drops

Fig. 4 Experimental and theoretical description of palladium sites. Most relevant surface models representing the CP and DI catalyst in fresh, activated, and used forms and their main features derived from experiments and theory. The color code for the atoms in the models is the same as described in caption to Fig. 3

reaction was also favored (activation energy decreased by ca. $10 \%$, Fig. 5a), supporting the dual beneficial-detrimental action of palladium nanoparticles. In line with these results, a low activation energy for the parasitic reaction was also determined for $\mathrm{Pd} / \mathrm{TiO}_{2}$. Similarly, $\mathrm{In}_{2} \mathrm{O}_{3}$ surfaces containing three or more exposed $\mathrm{Pd}$ atoms form $\mathrm{CO}$ rather than methanol and the $\mathrm{Pd}$ (111) surface is associated with the lowest activation barrier for the RWGS reaction of all models (Supplementary Table 6). The experimental measurements additionally indicate that a fourfold higher methanol STY $\left(1.01 \mathrm{~g}_{\mathrm{MeOH}} \mathrm{h}^{-1} \mathrm{~g}_{\mathrm{cat}}-1, \mathrm{CO}_{2}\right.$ conversion $=$ $9.7 \%$, methanol selectivity $=78 \%$ ) can be attained over the $\mathrm{CP}$ material at a $20-\mathrm{K}$ lower temperature than for $\operatorname{In}_{2} \mathrm{O}_{3}$, implying higher productivity with lower energy input. The $\mathrm{CP}$ and equilibrated DI catalysts were further tested at variable partial pressures of reactants and products to derive their reaction orders (Table 1, Supplementary Figs. 22 and 23). The values obtained for $\mathrm{CO}_{2}$ and $\mathrm{H}_{2}$ for both catalysts are close to 0 , thus being equal and substantially lower than for $\operatorname{In}_{2} \mathrm{O}_{3}^{22}$, respectively. The reaction order for methanol was barely altered by palladium addition through either synthesis method, whereas the lower reaction order for $\mathrm{H}_{2}$ indicates superior $\mathrm{H}_{2}$ splitting ability over both systems. The negative rate dependence on the water pressure was greatly alleviated for the $\mathrm{CP}$ catalyst, whereas no significant change compared to $\operatorname{In}_{2} \mathrm{O}_{3}$ was determined for the DI sample. Facilitated water desorption represents a strong contributor to catalyst stability, as water-induced sintering is a major deactivation mechanism for the pure oxide ${ }^{22}$, whereby we speculate that surface $\mathrm{OH}$ groups condensation likely drives the coalescence of $\mathrm{In}_{2} \mathrm{O}_{3}$ crystals. This was corroborated by an extended test over the $\mathrm{CP}$ material aged for $200 \mathrm{~h}$ (Fig. 1b). Owing to the portion of palladium in the lattice, the material did not exhibit pronounced performance deterioration over $80 \mathrm{~h}$ (Fig. 1b). As expected, the methanol STY was overall inferior $\left(0.54\right.$ versus $0.61 \mathrm{~g}_{\mathrm{MeOH}} \mathrm{h}^{-1}$ $\mathrm{g}_{\mathrm{cat}}{ }^{-1}$ ) to the CP catalyst aged for $1 \mathrm{~h}$ since the methanol selectivity was reduced by the presence of the palladium particles $(64 \%$ versus $80 \%$, Supplementary Fig. 19). As the methanol production rate was almost constant upon altering the $\mathrm{H}_{2}: \mathrm{CO}_{2}$ ratio, the $\mathrm{CP}$ catalyst could be practically operated with a sub-stoichiometric $\mathrm{H}_{2}$ feed, thus greatly lowering the size of the recycle stream needed in the process, which will substantially reduce investment and operating costs for reactor, heat exchangers, and compressors $^{46}$. Applying the optimal conditions identified in the 
a
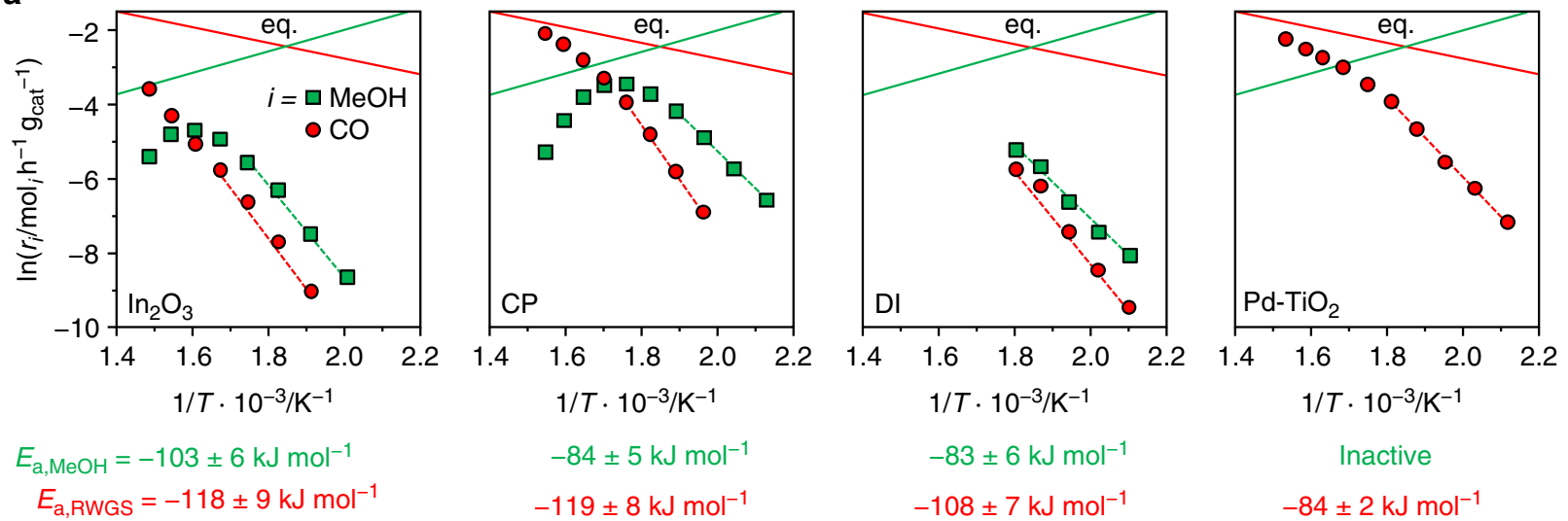

b
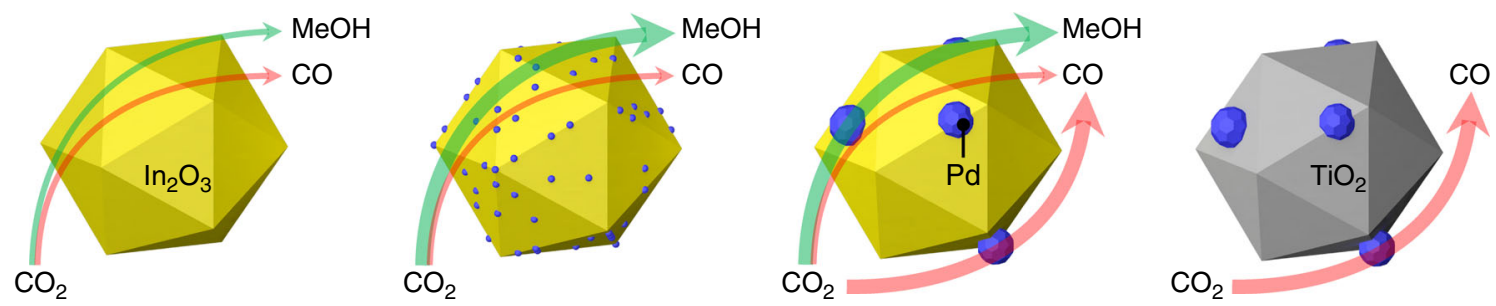

Fig. 5 Activation energies and palladium role for palladium-promoted $\ln _{2} \mathrm{O}_{3}$ catalysts. a Arrhenius plots and calculated apparent activation energies ( $E_{a}$ ) for $\mathrm{CO}_{2}$ hydrogenation to methanol (green) and the RWGS reaction (red) over $\ln _{2} \mathrm{O}_{3}, \mathrm{CP}, \mathrm{DI}$, and Pd-TiO $\mathrm{O}_{2}$ catalysts. Data regression was performed in the region outlined by the dashed lines. Solid lines indicate the thermodynamic equilibria of the two independent reactions. $\mathbf{b}$ Schematic representation of the distinct role of palladium in equilibrated $\mathrm{CP}$ and $\mathrm{DI}$ systems with $\mathrm{In}_{2} \mathrm{O}_{3}$ and $\mathrm{Pd}-\mathrm{TiO}_{2}$ as references. The thickness of the arrows qualitatively indicates the products formation rates. Reaction conditions: $P=5 \mathrm{MPa}, \mathrm{H}_{2}: \mathrm{CO}_{2}=4$, and $W H S V=48,000 \mathrm{~cm}^{3} \mathrm{sTP} \mathrm{h}^{-1} \mathrm{~g}_{\text {cat }}{ }^{-1}$

\begin{tabular}{|c|c|c|c|c|}
\hline Catalyst $^{\mathbf{a}}$ & $n_{\mathrm{CO} 2}[-]$ & $n_{\mathrm{H} 2}[-]$ & $n_{\mathrm{MeOH}}[-]$ & $n_{\mathrm{H} 2 \mathrm{O}}[-]$ \\
\hline $\mathrm{In}_{2} \mathrm{O}_{3}$ & -0.1 & $0.5-0.8$ & -0.2 & -0.8 \\
\hline $\mathrm{CP}$ & -0.1 & 0.2 & -0.3 & -0.5 \\
\hline DI & -0.1 & 0.3 & -0.2 & -0.9 \\
\hline
\end{tabular}

aApparent reaction orders $\left(n_{i}\right)$ extracted by data regression from catalytic tests at variable partial pressures of $\mathrm{CO}_{2}, \mathrm{H}_{2}$, water, and methanol (Supplementary Figs. 22 and 23).

kinetic analysis $\left(\mathrm{H}_{2}: \mathrm{CO}_{2}=4, P=5 \mathrm{MPa}, \quad T=553 \mathrm{~K}\right.$, and $\left.W H S V=48,000 \mathrm{~cm}^{3}{ }_{\text {STP }} \mathrm{h}^{-1} \mathrm{~g}_{\text {cat }}{ }^{-1}\right)$, catalyst durability was assessed in a 500-h test (Fig. 6). The $\mathrm{CO}_{2}$ conversion slightly dropped (from 9.7 to $9.2 \%$ ) and the methanol selectivity increased (from 75 to $78 \%$ ) in the first $200 \mathrm{~h}$, whereas remaining unaltered until the end of the run. The average particle size of $\operatorname{In}_{2} \mathrm{O}_{3}$ increased by only $2 \mathrm{~nm}$ compared with CP $96 \mathrm{~h}(17$ and $15 \mathrm{~nm}$, respectively). Owing to the addition of $\mathrm{TiO}_{2}$ as a diluent in this test, which could not be separated from the used catalyst, changes in porous properties and vacancy density could not be investigated. The methanol STY was $0.96 \mathrm{~g}_{\mathrm{MeOH}} \mathrm{h}^{-1} \mathrm{~g}_{\text {cat }}{ }^{-1}$, which is, to our knowledge, the highest sustained productivity reported for $\mathrm{CO}_{2}$-based methanol synthesis over a heterogeneous catalyst (Table 2). Specifically, our catalyst reaches a $15 \%$-higher methanol STY than the best performer reported and at a ca. $60 \%$ shorter residence time. The latter enables a reduction in reactor size by $60 \%$, which is a strong gain for a prospective industrial process. Moreover, CP is a synthesis method that has been successfully implemented for catalyst manufacture at the large scale for numerous applications, whereas the polymer-assisted route used for the benchmark appears of limited industrial amenability.

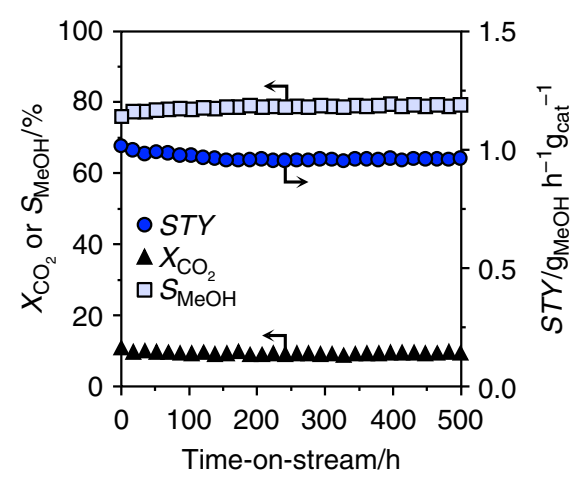

Fig. 6 Extended stability test of the best palladium-promoted $\ln _{2} \mathrm{O}_{3}$ catalyst. Evolution of the catalytic performance of the CP catalyst during a 500-h test conducted under optimized reaction conditions: $T=553 \mathrm{~K}, P=5 \mathrm{MPa}$, $\mathrm{H}_{2}: \mathrm{CO}_{2}=4$, and $W H S V=48,000 \mathrm{~cm}^{3} \mathrm{STP} \mathrm{h}^{-1} \mathrm{~g}_{\text {cat }}{ }^{-1}$

\section{Discussion}

We successfully produced a palladium-promoted $\mathrm{In}_{2} \mathrm{O}_{3}$ catalyst featuring palladium atomically dispersed in the oxide matrix by $\mathrm{CP}$ and a reference system comprising palladium nanoparticles by DI, the first showing a stable activity enhancement compared with bulk $\mathrm{In}_{2} \mathrm{O}_{3}$ exclusively directed to methanol production and the second displaying a decaying improvement of both methanol and $\mathrm{CO}$ formation. Extensive characterization by a battery of techniques, including solid-state ${ }^{115}$ In NMR, here introduced as a novel technique to elucidate vacancy formation and short-range crystallinity in (palladium-promoted) $\mathrm{In}_{2} \mathrm{O}_{3}$ catalysts, and theoretical modeling provided sound understanding of the structure and functioning of the active sites in the two systems. In the $\mathrm{CP}$ catalyst, embedding one $\mathrm{Pd}$ atom in the $\mathrm{In}_{2} \mathrm{O}_{3}$ matrix enables a 
Table 2 Comparison of heterogeneous catalysts for $\mathrm{CO}_{2}$ hydrogenation to methanol

\begin{tabular}{|c|c|c|c|c|c|c|}
\hline $\mathrm{Pd}-\ln _{2} \mathrm{O}_{3} \mathrm{CP}$ & 553 & 5 & 24,000 & 75 & 0.61 & This work \\
\hline $\mathrm{Pd}-\mathrm{Zn}$ & 543 & 2 & 18,000 & 70 & 0.60 & 56 \\
\hline LDH30-Ga & 543 & 4.5 & 18,000 & 49 & 0.59 & 57 \\
\hline $\mathrm{PdP}-\mathrm{In}_{2} \mathrm{O}_{3}$ & 593 & 5 & 21,000 & 67 & 0.89 & 28 \\
\hline $\mathrm{CeO}_{2} \mathrm{MoPK} / \mathrm{SiO}_{2}$ & 503 & 3.1 & 10,800 & 76 & 0.41 & 58 \\
\hline
\end{tabular}

controlled growth of extra-lattice atoms, leading to the stabilization of low-nuclearity palladium clusters. The number of vacancies does not increase but their electronic properties are strongly modified, permitting improved $\mathrm{H}_{2}$ dissociation. The small size of the palladium cluster is crucial to curtail the RWGS reaction on palladium sites, which is relevant already for clusters of 3 extra-lattice promoter atoms. In the DI catalyst, palladium steadily agglomerates with time on stream forming particles. These aid methanol production by supplying activated hydrogen that fosters the formation of surface vacancies on $\mathrm{In}_{2} \mathrm{O}_{3}$ and the hydrogenation of the $\mathrm{CO}_{2}$ therein adsorbed. Still, they consume a significant part of the $\mathrm{H}_{2}$ split by converting $\mathrm{CO}_{2}$ into $\mathrm{CO}$ on their own surface (Fig. $5 b$ ). These contrasting palladium speciations also explain the profoundly diverse time-on-stream behaviors of the two catalysts. Palladium embedded into indium oxide attracts the scarce palladium in pockets, avoiding its clustering, and facilitates water desorption minimizing $\mathrm{In}_{2} \mathrm{O}_{3}$ sintering, whereas palladium deposited onto $\operatorname{In}_{2} \mathrm{O}_{3}$ easily agglomerates and leads to catalyst sintering by spilling too much activated $\mathrm{H}_{2}$ to the oxide, causing over-reduction, and by excessively retaining water, provoking crystals coalescence. Hence, anchoring of palladium clusters to the $\operatorname{In}_{2} \mathrm{O}_{3}$ lattice is an unprecedented approach to effectively enhance activity and selectivity, and more importantly, to maintain the promotional effect in the long term, an aspect fully disregarded in previous studies on palladium-promoted $\mathrm{In}_{2} \mathrm{O}_{3}$ systems. In addition, low-nuclearity palladium clusters grant the possibility to operate the catalyst at reduced temperature, with hydrogen-lean feeds, and in the presence of greater amounts of water, altogether implying strong economic and ecologic benefits at a process level. Overall, our strategy to engineer promotion at the atomic scale marks a step ahead toward green methanol production and holds great general potential for tailoring new or existing promoted systems in current and emerging applications of heterogeneous catalysis.

\footnotetext{
Methods

Catalyst preparation. To obtain palladium-promoted (0.25-10 wt.\% Pd) $\operatorname{In}_{2} \mathrm{O}_{3}$ catalysts by co-precipitation, $\operatorname{In}\left(\mathrm{NO}_{3}\right)_{3} \cdot x \mathrm{H}_{2} \mathrm{O}(3.51,3.50,3.48,3.47,3.46,3.45,3.40$, or $3.20 \mathrm{~g}$, Sigma-Aldrich, $99.99 \%, x=6.9)$ and $\mathrm{Pd}\left(\mathrm{NO}_{3}\right)_{2} \cdot x \mathrm{H}_{2} \mathrm{O}(4.63,11.6,23.15$, 34.8, $46.3069 .6,162.5$, or $463 \mathrm{mg}$, Sigma-Aldrich, $>99.99 \%$ metals basis, $x=5.5$ ) were dissolved in deionized water $\left(50 \mathrm{~cm}^{3}\right)$ in a round-bottomed flask $\left(250 \mathrm{~cm}^{3}\right)$. $\mathrm{Na}_{2} \mathrm{CO}_{3}(10.0 \mathrm{~g})$ was dissolved in deionized water $\left(100 \mathrm{~cm}^{3}\right)$ and added dropwise (ca. $25 \mathrm{~cm}^{3}, 3 \mathrm{~cm}^{3} \mathrm{~min}^{-1}$ ) to the metals solution under stirring at room temperature to reach a $\mathrm{pH}$ value of 9.2. After aging the resulting slurry for $1 \mathrm{~h}$, deionized water was added $\left(50 \mathrm{~cm}^{3}\right)$. Then, the precipitate was recovered by highpressure filtration, washed with deionized water (three times, $500 \mathrm{~cm}^{3}$ each time), and dried in a vacuum oven $(1.5 \mathrm{kPa}, 323 \mathrm{~K}, 1.5 \mathrm{~h})$. To produce palladiumcontaining (0.25-3.5 wt.\% Pd) $\mathrm{In}_{2} \mathrm{O}_{3}$ catalysts by dry impregnation, a roundbottomed flask $\left(25 \mathrm{~cm}^{3}\right)$ was loaded with $\mathrm{Pd}\left(\mathrm{NO}_{3}\right)_{2} \cdot x \mathrm{H}_{2} \mathrm{O}(7.8,23.5$, or $109.4 \mathrm{mg})$ and deionized water $(0.39 \mathrm{~g})$. After adding $\operatorname{In}_{2} \mathrm{O}_{3}(1.00 \mathrm{~g})$ and five stainless-steel spheres (radius $=3 \mathrm{~mm}$ ), the flask was rotated (ca. 45 r.p.m.) using a Büchi R-114 rotary evaporator at room temperature and pressure. After $12 \mathrm{~h}$, the pressure was lowered to $2 \mathrm{kPa}$ and the temperature raised to $333 \mathrm{~K}$ for $1 \mathrm{~h}$ to allow the evaporation of the solvent. Catalysts were calcined for $3 \mathrm{~h}$ at $573 \mathrm{~K}\left(2 \mathrm{~K} \mathrm{~min}^{-1}\right)$ in
}

static air prior to characterization or catalytic testing. The syntheses of all other materials reported in this study are detailed in the Supplementary Methods.

Catalyst characterization. The metal content of the catalysts was determined by inductively coupled plasma optical emission spectrometry. When $\mathrm{Na}_{2} \mathrm{CO}_{3}$ was used as the precipitating agent, the absence of sodium in calcined materials was confirmed by X-ray fluorescence spectroscopy as well as by STEM-EDX and XPS for selected materials. The water amount in In and Pd precursors was derived from thermogravimetric analysis. Porous and structural properties of the catalysts were assessed by $\mathrm{N}_{2}$ sorption and powder XRD. Palladium dispersion, speciation and coordination geometry, and reducibility were accessed by volumetric chemisorption of $\mathrm{H}_{2}$ and CO, CO-DRIFTS, STEM-EDX, and HRTEM, X-ray absorption spectroscopy (XAS), TOF-SIMS, and by TPR. Surface concentration and oxidation states of $\mathrm{C}, \mathrm{O}, \mathrm{Pd}$, and In were determined by XPS. Oxygen vacancies and $\mathrm{CO}_{2}$ adsorption capacity were characterized by XPS, ${ }^{115}$ In NMR, and TPR and TPD methods. Details to the characterization techniques are provided in the Supplementary Methods and in Supplementary Fig. 24.

Catalytic testing. $\mathrm{CO}_{2}$ hydrogenation to methanol was conducted in a highpressure continuous-flow fixed-bed reactor setup comprising mass flow controllers to feed gases (Bronkhorst, El-Flow F-201CV), pneumatic valves, a reactor with an inner diameter of $2.2 \mathrm{~mm}$ housed in an electrically-heated aluminum brass furnace, a pressure transducer, a burst plate calibrated at $6 \mathrm{MPa}$, a syringe pump to feed liquids (Chemyx Nexus 6000), an online gas chromatograph (Agilent $7890 \mathrm{~A}$ equipped with Agilent DB-1 and GS-GasPro columns), and a computer control by a custom protocol within the LabView software. In a typical test, the reactor was loaded with $100 \mathrm{mg}$ of catalyst with a particle size of $100-125 \mu \mathrm{m}$, which was held in place by a bed of quartz wool and heated from ambient temperature to $553 \mathrm{~K}$ $\left(5 \mathrm{~K} \mathrm{~min}^{-1}\right)$ at $5 \mathrm{MPa}$ under a He flow $\left(20 \mathrm{~cm}^{3} \mathrm{~min}^{-1}\right)$. After $3 \mathrm{~h}$, the gas flow was switched to the reactant mixture $\left(40 \mathrm{~cm}^{3} \mathrm{~min}^{-1}\right)$ comprising $\mathrm{H}_{2}$ and $\mathrm{CO}_{2}$ (Messer, $99.997 \%$ and $99.999 \%$, respectively) in a molar ratio of $4: 1$. For kinetic tests, temperature $(473-653 \mathrm{~K})$ and inlet partial pressures of reagents $\left(p_{\mathrm{H} 2}=3.5-4.5\right.$ $\left.\mathrm{MPa}, p_{\mathrm{CO} 2}=0.5-1.5 \mathrm{MPa}\right)$ and products $\left(p_{\mathrm{MeOH}}\right.$ and $\left.p_{\mathrm{H} 2 \mathrm{O}}=0.05-0.25 \mathrm{MPa}\right)$ were varied at a doubled $W H S V$ attained by loading only $50 \mathrm{mg}$ of catalyst diluted in $50 \mathrm{mg}$ of $\mathrm{TiO}_{2}(100-125 \mu \mathrm{m}$, Sigma-Aldrich, $>99.9 \%)$. Water (ABCR-Chemicals, HPLC grade) or methanol (Sigma-Aldrich, $>99.9 \%$, anhydrous) were fed to the reactor inlet by a high-pressure syringe pump (Chemyx, Nexus 6000). The effluent stream was sampled every $12 \mathrm{~min}$ and analyzed by online gas chromatography. Data evaluation procedures are presented in the Supplementary Methods and details to all catalytic tests are compiled in Supplementary Table 7.

DFT. DFT simulations were performed using the Vienna Ab initio Simulation Package (VASP) ${ }^{47,48}$ using the Perdew-Burke-Ernzerhof density functional ${ }^{49}$. Valence electrons were described with a plane-wave energy cutoff of $500 \mathrm{eV}$, whereas core electrons were represented by projector augmented-wave pseudopotentials ${ }^{50}$. The $\operatorname{In}_{2} \mathrm{O}_{3}(111)$ surface was modeled as a $\mathrm{p}(1 \times 1)$ slab containing five $\mathrm{O}-\mathrm{In}-\mathrm{O}$ trilayers and optimized using a $\Gamma$-centered $(3 \times 3 \times 1) k$-point mesh. In each surface, the three outermost $\mathrm{O}-\mathrm{In}-\mathrm{O}$ trilayers were allowed to relax, whereas the two bottommost layers were fixed in their bulk positions. The initial structure of the CP catalyst was modeled by substituting an In atom in the $\operatorname{In}_{3} \mathrm{O}_{5}(\mathrm{O})$ ensemble by a Pd atom. Three further structures include the addition of 1-3 Pd atoms bonded to the Pd atom in the oxide lattice. For the DI catalyst, 1-3 Pd atoms were added in the concave zone of the $\operatorname{In}_{2} \mathrm{O}_{3}(111)$ surface. For both types of catalysts, $\mathrm{O}$ vacancy formation and palladium migration were explored. Energy profiles for $\mathrm{CO}_{2}$ hydrogenation to methanol and $\mathrm{CO}$ were calculated using the most feasible paths identified in our previous study ${ }^{22}$ on all CP and DI models, including the water-assisted step in the RWGS. To reduce the number of steps, the adsorption of the third $\mathrm{H}_{2}$ molecule was moved after $\mathrm{H}_{2} \mathrm{COOH}$ formation. The reaction network occurring on the $\mathrm{Pd}(111)$ surface, representing the palladium nanoparticles in the equilibrated DI sample, was also taken from previous studies $^{35,45}$. The Gibbs free energies of the adsorbed species considered only vibrational contributions. For gas phase, translational and rotational terms were 
also included and obtained from Gaussian $09^{51}$. The reaction network was interrogated through a microkinetic model based on a differential reactor under steadystate conditions. The kinetic parameters were modeled from transition state theory, whereas adsorption processes followed the Hertz-Knudsen equation ${ }^{46}$. The resulting system of equations was resolved in Maple using a floating-point precision of 96 digits. The temperatures and pressures of operation were chosen to match the experimental ones. For relevant systems, the XPS core-level Pd $3 d$ shifts were computed in VASP, using metallic Pd as reference ${ }^{52}$, and were compared with the Bader charges (Supplementary Table 9). EXAFS spectra were obtained from XAS simulations attained using feff ${ }^{53}$ after processing with Athena ${ }^{54}$ in the same way as for the experimental data and subsequent normalization.

\section{Data availability}

The authors declare that the data supporting the findings of this study are available within the article and its Supplementary Information file. All DFT data and the corresponding structures are accessible at the ioChem-BD database ${ }^{55}$ following the link: https://doi.org/10.19061/iochem-bd-1-106. All other relevant source data are available from the corresponding author upon reasonable request.

Received: 1 May 2019 Accepted: 26 June 2019

Published online: 29 July 2019

\section{References}

1. Bartholomew, C. H. \& Farrauto, R. J. Fundamentals of Industrial Catalytic Processes (Wiley, Hoboken, 2006).

2. Hutchings, G. J. Promotion in heterogeneous catalysis: a topic requiring a new approach? Catal. Lett. 75, 1-12 (2001).

3. van Santen, R. A. Chemical basis of metal catalyst promotion. Surf. Sci. 251252, 6-11 (1991).

4. Sheng, H. \& Lobo, R. F. Iron-promotion of silica-supported copper catalysts for furfural hydrodeoxygenation. ChemCatChem 8, 3402-3408 (2016).

5. Kondratenko, E. V., Mul, G., Baltrusaitis, J., Larrazábal, G. O. \& PérezRamírez, J. Status and perspectives of $\mathrm{CO}_{2}$ conversion into fuels and chemicals by catalytic, photocatalytic and electrocatalytic processes. Energ. Environ. Sci. 6, 3112-3135 (2013).

6. Olah, G. A. Beyond oil and gas: the methanol economy. Angew. Chem. Int. Ed. 44, 2636-2639 (2005).

7. Ali, K. A., Abdullah, A. Z. \& Mohamed, A. R. Recent development in catalytic technologies for methanol synthesis from renewable sources: a critical review. Renew. Sust. Energ. Rev. 44, 508-518 (2015).

8. Behr, A. Methanol: the basic chemical and energy feedstock of the future. Angew. Chem. Int. Ed. 53, 12674-12674 (2014).

9. Álvarez, A. et al. Challenges in the greener production of formates/formic acid, methanol, and DME by heterogeneously catalyzed $\mathrm{CO}_{2}$ hydrogenation processes. Chem. Rev. 117, 9804-9838 (2017).

10. Wang, J. et al. A highly selective and stable $\mathrm{ZnO}-\mathrm{ZrO}_{2}$ solid solution catalyst for $\mathrm{CO}_{2}$ hydrogenation to methanol. Sci. Adv. 3, e1701290 (2017).

11. Vogt, C. et al. Unravelling structure sensitivity in $\mathrm{CO}_{2}$ hydrogenation over nickel. Nat. Catal. 1, 127-134 (2018).

12. Wang, L. et al. Incorporating nitrogen atoms into cobalt nanosheets as a strategy to boost catalytic activity toward $\mathrm{CO}_{2}$ hydrogenation. Nat. Energy 2 , 869-876 (2017).

13. Behrens, M. Promoting the synthesis of methanol: understanding the requirements for an industrial catalyst for the conversion of $\mathrm{CO}_{2}$. Angew. Chem. Int. Ed. 55, 14906-14908 (2016).

14. $\mathrm{Xu}$, J. et al. Methanol synthesis from $\mathrm{CO}_{2}$ and $\mathrm{H}_{2}$ over $\mathrm{Pd} / \mathrm{ZnO} / \mathrm{Al}_{2} \mathrm{O}_{3}$ : catalyst structure dependence of methanol selectivity. Appl. Catal. A 514, 51-59 (2016).

15. Yang, H. B. et al. Atomically dispersed $\mathrm{Ni}(\mathrm{I})$ as the active site for electrochemical $\mathrm{CO}_{2}$ reduction. Nat. Energy 3, 140-147 (2018).

16. Loiland, J. A., Wulfers, M. J., Marinkovic, N. S. \& Lobo, R. F. Fe $/ \gamma-\mathrm{Al}_{2} \mathrm{O}_{3}$ and $\mathrm{Fe}-\mathrm{K} / \gamma-\mathrm{Al}_{2} \mathrm{O}_{3}$ as reverse water-gas shift catalysts. Catal. Sci. Technol. 6, 5267-5279 (2016).

17. Martin, O. et al. Indium oxide as a superior catalyst for methanol synthesis by $\mathrm{CO}_{2}$ hydrogenation. Angew. Chem. Int. Ed. 55, 6261-6265 (2016).

18. Gao, P. et al. Direct conversion of $\mathrm{CO}_{2}$ into liquid fuels with high selectivity over a bifunctional catalyst. Nat. Chem. 9, 1019-1024 (2017).

19. Zhang, S. et al. Solid frustrated-Lewis-pair catalysts constructed by regulations on surface defects of porous nanorods of $\mathrm{CeO}_{2}$. Nat. Commun. 8, 15266 (2017).

20. Ghuman, K. K. et al. Photoexcited surface frustrated Lewis pairs for heterogeneous photocatalytic $\mathrm{CO}_{2}$ reduction. J. Am. Chem. Soc. 138, 1206-1214 (2016).
21. Albani, D. et al. Semihydrogenation of acetylene on indium oxide: proposed single-ensemble catalysis. Angew. Chem. Int. Ed. 56, 10755-10760 (2017).

22. Frei, M. S. et al. Mechanism and microkinetics of methanol synthesis via $\mathrm{CO}_{2}$ hydrogenation on indium oxide. J. Catal. 361, 313-321 (2018).

23. Ye, J., Liu, C.-j, Mei, D. \& Ge, Q. Methanol synthesis from $\mathrm{CO}_{2}$ hydrogenation over a $\mathrm{Pd}_{4} / \mathrm{In}_{2} \mathrm{O}_{3}$ model catalyst: a combined DFT and kinetic study. J. Catal. 317, 44-53 (2014)

24. Lorenz, H. et al. $\mathrm{Pd}-\mathrm{In}_{2} \mathrm{O}_{3}$ interaction due to reduction in hydrogen: consequences for methanol steam reforming. Appl. Catal. A 374, 180-188 (2010).

25. Rameshan, C. et al. Impregnated and co-precipitated $\mathrm{Pd}-\mathrm{Ga}_{2} \mathrm{O}_{3}, \mathrm{Pd}-\mathrm{In}_{2} \mathrm{O}_{3}$ and $\mathrm{Pd}-\mathrm{Ga}_{2} \mathrm{O}_{3}-\mathrm{In}_{2} \mathrm{O}_{3}$ catalysts: influence of the microstructure on the $\mathrm{CO}_{2}$ selectivity in methanol steam reforming. Catal. Lett. 148, 3062-3071 (2018).

26. García-Trenco, A. et al. PdIn intermetallic nanoparticles for the hydrogenation of $\mathrm{CO}_{2}$ to methanol. Appl. Catal. B 220, 9-18 (2018).

27. Ye, J., Ge, Q. \& Liu, C.-J. Effect of PdIn bimetallic particle formation on $\mathrm{CO}_{2}$ reduction over the $\mathrm{PdIn} / \mathrm{SiO}_{2}$ catalyst. Chem. Eng. Sci. 135, 193-201 (2015).

28. Rui, N. et al. $\mathrm{CO}_{2}$ hydrogenation to methanol over $\mathrm{Pd} / \mathrm{In}_{2} \mathrm{O}_{3}$ : effects of $\mathrm{Pd}$ and oxygen vacancy. Appl. Catal. B 218, 488-497 (2017).

29. Arena, F. et al. Solid-state interactions, adsorption sites and functionality of $\mathrm{Cu}-\mathrm{ZnO} / \mathrm{ZrO}_{2}$ catalysts in the $\mathrm{CO}_{2}$ hydrogenation to $\mathrm{CH}_{3} \mathrm{OH}$. Appl. Catal. A 350, 16-23 (2008).

30. Erdöhelyi, A., Pásztor, M. \& Solymosi, F. Catalytic hydrogenation of $\mathrm{CO}_{2}$ over supported palladium. J. Catal. 98, 166-177 (1986).

31. Pettigrew, D. J., Trimm, D. L. \& Cant, N. W. The effects of rare earth oxides on the reverse water-gas shift reaction on palladium/alumina. Catal. Lett. 28, 313-319 (1994).

32. Vilé, G. et al. A stable single-site palladium catalyst for hydrogenations Angew. Chem. Int. Ed. 54, 11265-11269 (2015).

33. Mitchell, S., Vorobyeva, E. \& Pérez-Ramírez, J. The multifaceted reactivity of single-atom heterogeneous catalysts. Angew. Chem. Int. Ed. 130, 15538-15552 (2018).

34. Gao, G., Jiao, Y., Waclawik, E. R. \& Du, A. Single atom (Pd/Pt) supported on graphitic carbon nitride as an efficient photocatalyst for visible-light reduction of carbon dioxide. J. Am. Chem. Soc. 138, 6292-6297 (2016).

35. Li, Q., García-Muelas, R. \& López, N. Microkinetics of alcohol reforming for $\mathrm{H}_{2}$ production from a fair density functional theory database. Nat. Commun. 9, 526 (2018).

36. Li, H. et al. Synergetic interaction between neighbouring platinum monomers in $\mathrm{CO}_{2}$ hydrogenation. Nat. Nanotechnol. 13, 411-417 (2018).

37. Nørskov, J. K., Bligaard, T., Rossmeisl, J. \& Christensen, C. H. Towards the computational design of solid catalysts. Nat. Chem. 1, 37-46 (2009).

38. Medford, A. J. et al. From the Sabatier principle to a predictive theory of transition-metal heterogeneous catalysis. J. Catal. 328, 36-42 (2015).

39. Jimenez-Izal, E. \& Alexandrova, A. N. Computational design of clusters for catalysis. Annu. Rev. Phys. Chem. 69, 377-400 (2018).

40. Tauster, S. Strong metal-support interactions. Acc. Chem. Res. 20, 389-394 (1987).

41. Abbet, $\mathrm{S}$. et al. Identification of defect sites on $\mathrm{MgO}(100)$ thin films by decoration with $\mathrm{Pd}$ atoms and studying $\mathrm{CO}$ adsorption properties. J. Am. Chem. Soc. 123, 6172-6178 (2001).

42. Bergeret, G. \& Gallezot, P. in Handbook of Heterogeneous Catalysis Vol. 2. (eds Ertl, G., Knözinger, H., Schüth, F. \& Weitkamp, J.) 738-765 (Wiley-VCH, Weinheim, 2008).

43. Capdevila-Cortada, M. \& López, N. Entropic contributions enhance polarity compensation for $\mathrm{CeO}_{2}(100)$ surfaces. Nat. Mater. 16, 328-334 (2017).

44. Snider, J. L. et al. Revealing the synergy between oxide and alloy phases on the performance of bimetallic In-Pd catalysts for $\mathrm{CO}_{2}$ hydrogenation to methanol. ACS Catal. 9, 3399-3412 (2019).

45. García-Muelas, R., Li, Q. \& López, N. Density functional theory comparison of methanol decomposition and reverse reactions on metal surfaces. ACS Catal. 5, 1027-1036 (2015).

46. Chorkendorff, I. \& Niemantsverdriet, J. W. in Concepts of Modern Catalysis and Kinetics Vol. 1 (eds Chorkendorff, I. \& Niemantsverdriet) 79-128 (WileyVCH, Weinheim, 2003)

47. Kresse, G. \& Furthmüller, J. Efficiency of ab-initio total energy calculations for metals and semiconductors using a plane-wave basis set. Comput. Mater. Sci. 6, 15-50 (1996).

48. Kresse, G. \& Hafner, J. Ab initio molecular dynamics for liquid metals. Phys. Rev. B47, 558-561 (1993).

49. Perdew, J. P., Burke, K. \& Ernzerhof, M. Generalized gradient approximation made simple, Phys. Rev. Lett. 77, 3865-3868 (1996).

50. Blöchl, P. E. Projector augmented-wave method, Phys. Rev. B50, 17953-17979 (1994).

51. Frisch, M. J. et al. Gaussian 09, Revision A.02. (Gaussian, Inc., Wallingford CT, 2016).

52. Köhler, L. \& Kresse, G. Density functional study of $\mathrm{CO}$ on $\mathrm{Rh}(111)$. Phys. Rev. $B$ 70, 165405 (2004). 
53. Newville, M. EXAFS analysis using FEFF and FEFFIT. J. Synchrotron Radiat. 8, 96-100 (2001)

54. Ravel, B. \& Newville, M. ATHENA, ARTEMIS, HEPHAESTUS: data analysis for X-ray absorption spectroscopy using IFEFFIT. J. Synchrotron Radiat. 12, 537-541 (2005).

55. Álvarez-Moreno, M. et al. Managing the computational chemistry big data problem: the ioChem-BD platform. J. Chem. Inf. Model. 55, 99-103 (2015)

56. Liao, F. et al. A promising low pressure methanol synthesis route from $\mathrm{CO}_{2}$ hydrogenation over Pd@Zn core-shell catalysts. Green. Chem. 19, 270-280 (2017).

57. $\mathrm{Li}, \mathrm{M}$. M. J. et al. $\mathrm{CO}_{2}$ hydrogenation to methanol over catalysts derived from single cationic layer CuZnGa LDH precursors. ACS Catal. 8, 4390-4401 (2018).

58. Duyar, M. S. et al. A highly active molybdenum phosphide catalyst for methanol synthesis from $\mathrm{CO}$ and $\mathrm{CO}_{2}$. Angew. Chem. Int. Ed. 57, 15045-15050 (2018).

\section{Acknowledgements}

Total Research \& Technology Feluy is thanked for sponsoring this project. R.G.-M. thanks the AGAUR 2017 SGR 90 project for financial support. BSC-RES is acknowledged for generous computational resources. S. Mitchell is thanked for the electron microscopy measurements, L. Piveteau and R. Verel for help with the acquisition and analysis of NMR spectra, the Scientific Center for Optical and Electron Microscopy (ScopeM) at the ETH Zurich and the NMR-Service of the Institute for Chemical and Bioengineering at the ETH Zurich, for the use of their facilities, and Marçal Capdevila-Cortada for useful discussions.

\section{Author contributions}

J.P.-R. and C.M. conceived and coordinated all stages of this research. M.S.F., K.S.K. and B.P. prepared and characterized the catalysts and conducted the catalytic tests. O.V.S. coordinated acquisition and evaluation of X-ray absorption spectroscopy data. R.G.-M. and N.L. conducted the computational studies. J.A.S. and D.C.F. contributed in setting industrial targets for the experimental program. All authors contributed to the writing of the manuscript.

\section{Additional information}

Supplementary Information accompanies this paper at https://doi.org/10.1038/s41467019-11349-9.

Competing interests: The authors declare no competing interests.

Reprints and permission information is available online at http://npg.nature.com/ reprintsandpermissions/

Peer review information: Nature Communications thanks Yuhan Sun, and the other, anonymous, reviewer(s) for their contribution to the peer review of this work. Peer reviewer reports are available.

Publisher's note: Springer Nature remains neutral with regard to jurisdictional claims in published maps and institutional affiliations.

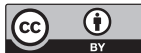

Open Access This article is licensed under a Creative Commons Attribution 4.0 International License, which permits use, sharing, adaptation, distribution and reproduction in any medium or format, as long as you give appropriate credit to the original author(s) and the source, provide a link to the Creative Commons license, and indicate if changes were made. The images or other third party material in this article are included in the article's Creative Commons license, unless indicated otherwise in a credit line to the material. If material is not included in the article's Creative Commons license and your intended use is not permitted by statutory regulation or exceeds the permitted use, you will need to obtain permission directly from the copyright holder. To view a copy of this license, visit http://creativecommons.org/ licenses/by/4.0/.

(c) The Author(s) 2019 